\title{
Comparison of Continuous Versus Intermittent Administration of Triptorelin on the Final Height of Girls with Idiopathic Precocious Puberty
}

\author{
Zohreh Karamizadeh, ${ }^{1}$ Ahmad Reza Rasekhi, ${ }^{2,}$ Sara Kashef, ${ }^{3}$ Forough Saki, ${ }^{4}$ and Soheil \\ Ashkani-Esfahani ${ }^{5}$ \\ ${ }^{1}$ Neonatology Research Center, Shiraz University of Medical Sciences, Shiraz, IR Iran \\ ${ }^{2}$ Department of General Surgery, Shiraz University of Medical Sciences, Shiraz, IR Iran \\ ${ }^{3}$ Allergy Research Center, Shiraz University of Medical Sciences, Shiraz, IR Iran \\ ${ }^{4}$ Shiraz Endocrinology and Metabolic Research Center, Shiraz University of Medical Sciences, Shiraz, IR Iran \\ ${ }^{5}$ Student Research Committee, Shiraz University of Medical Sciences, Shiraz, IR Iran \\ "Corresponding author: Ahmad Reza Rasekhi, Department of General Surgery, Shiraz University of Medical Sciences, Shiraz, IR Iran. E-mail: soashkani@gmail.com
}

Received 2016 June 11; Revised 2017 January 18; Accepted 2017 March 03.

\begin{abstract}
Background: It has long been reported that gonadotropin releasing hormone (GnRH) analogs can improve final height of patients with idiopathic precocious puberty (IPP). This study aimed at comparing 2 different doses of GnRH agonist, triptorelin, on the adult height of girls with IPP.

Methods: From July 2013, sixteen girls with IPP were randomly divided to 2 groups. The first Group received 1 intramuscular injection of triptorelin $0.3 \mathrm{mg} / \mathrm{kg}$ of body weight on a monthly basis, and the second group received this at months 1 to 6,10 to 15 , and 19 to 24. They did not receive triptorelin at months 7 to 9 and 16 to 18 .

Results: Patients in Group 1 received a total of $7.2 \mathrm{mg} / \mathrm{kg}$ of triptorelin during a 2-year follow up while the Group 2 received $5.4 \mathrm{mg} / \mathrm{kg}$ triptorelin or about $39.6 \mathrm{mg}$ less than the other group during the same period of follow up. No side effects were noted in Group 2 receiving lower dose of triptorelin, yet, 2 cases with gray hair and 1 case with mild rash were reported in the group receiving the higher dose. No statistically significant difference was found between the 2 groups regarding height after 2 years.

Conclusions: Treatment of IPP can be performed with triptorelin doses of less than $0.3 \mathrm{mg} / \mathrm{kg}$ per month, with the same height increment and lower side effects.
\end{abstract}

Keywords: Triptorelin, Idiopathic Precocious Puberty, Gonadotropin Releasing Hormone Analog, Height

\section{Background}

For more than 20 years, gonadotropin releasing hormone (GnRH) analogs have been used in the treatment of idiopathic precocious puberty (IPP) $(1,2)$. By influencing the pituitary gland, the release of follicular stimulating hormone (FSH) and luteinizing hormone ( $\mathrm{LH})$ is stimulated by triptorelin, a synthetic form of hypothalamic $\mathrm{GnRH}$, and its analogs $(1,2)$. Endogenous GnRH release is pulsatile and reined by several modulators including sex hormones. A long-acting GnRH, when used for a long duration, induces desensitization of pituitary $\mathrm{GnRH}$ receptors and final block of secretion after a short period of LH release. With adequate therapy, secondary sexual maturation is suppressed in a reversible manner, taking about 3 to 12 months after discontinuation $(2,3)$. Several side effects, including sexual dysfunction, gastrointestinal upset, mood disorders, breast swelling, graying of hair, dry skin, alterations in liver function, menopausal symptoms, rash, tumor flare, urticaria, acne, and hair loss have been reported $(1,3,4)$. The occurrence of these side effects is assumed to be directly related to the dose of the drug, thus, every effort should be made to reduce the dose with noticeable influence on the final outcome (5). In this regard, maintaining the pharmaceutical effects of the agent with the lowest possible dosage is the goal of many studies in this field.

This prospective study aimed at comparing the final heights of patients with IPP in 2 groups treated with 2 different doses of triptorelin during a 2-year follow up.

\section{Methods}

From July 2013, sixteen girls with a mean age of 7.05 years with diagnosis of IPP were chosen and followed up during the study. Other causes of precocious puberty were ruled out by means of clinical and paraclinical tests consisting of ultrasonography of abdomen, pelvic area, and adrenal glands, assessment of bone age, computed tomog- 
raphy (CT) scan, Magnetic resonance imaging (MRI) of the brain (with and without contrast), which were performed for all cases after obtaining written informed consent from the patients' parents. Androgen response to ACTH test (Cosyntropin test) and adrenal ultrasonography were performed to exclude congenital adrenal hyperplasia (CAH). Based on the manifestations of secondary sexual characteristics at the age of 8 years or younger, or the occurrence of menarche in these patients before the age of 10 years, final diagnosis of IPP was considered (6).

The patients were divided in a random manner to 2 equal groups, each including 8 girls. Group 1 received longacting GnRH agonist triptorelin (IPSEN Pharma Biotech, Signes, France) with a dosage of $0.3 \mathrm{mg} / \mathrm{kg}$, intramuscularly (IM), every month for a total of 24 months. Group 2 received triptorelin with a dosage of $0.3 \mathrm{mg} / \mathrm{kg}$ IM at months 1 to 6,10 to 15 , and 19 to 24 . They did not receive triptorelin at months 7 to 9 and 16 to 18 .

The study protocol was clarified for the patients and their parents, and written informed consent was obtained. Patients' data including age, weight, height, Tanner stages of puberty, bone age, growth rate, and estimated adult height were determined in the first visit and also before each injection, every month. The participants were followed up for at least 2 consecutive years. During each visit, height, weight, secondary sexual manifestations such as pubic hair, breast growth, occurrence of menarche, and any side effects of the drug, were evaluated carefully by a trained physician.

The protocol of the study was approved by the research ethics committee of Shiraz University of Medical Sciences, Shiraz, Iran.

For the statistical analyses, the SPSS software version 21.0 was used and the data were compared by nonparametric Student's t test. P values of $\leq 0.05$ were considered statistically significant.

\section{Results}

The range of patients' age was between 6 and 7.9 years with a mean of 7.05 years. The difference between age and height of the patients in Groups 1 and 2 were not statistically significant at the first visit.

Patients in Group 1 received a total of $7.2 \mathrm{mg} / \mathrm{kg}$ triptorelin during a 2-year follow up while Group 2 received 5.4 $\mathrm{mg} / \mathrm{kg}$ triptorelin during the same period of follow up.

Although a mean difference of $0.5 \mathrm{~cm}$ between heights of the 2 groups was observed between continuous versus non-continuous administration of triptorelin, it was not significant. Mean predicted adult height in group 1 was 158 $\pm 8.6 \mathrm{~cm}$, while in group 2 this was $159 \pm 7.6 \mathrm{~cm}$ with no considerable difference between the 2 groups. Sex maturity rates (SMR) and attained heights in each visit in group 1 , who received continuous triptorelin therapy, and Group 2 , which received non-continuous triptorelin therapy, are shown in Tables 1 and 2. Comparing the heights of patients in Groups 1 and 2 in each visit indicated no statistical difference (Table 3). Mean height before each injection in both groups and their statistical differences are shown in Table 3.

Bone ages before therapy in groups 1 and 2 were $8.9 \pm$ 1.2 years and $9.1 \pm 1.4$ years, respectively; after the therapy they were $9.5 \pm 0.9$ and $9.6 \pm 0.8$ years, respectively. None of the P values was significant.

No untoward side effect was noted in Group 2, which received a lower dose of triptorelin, yet, 2 cases of gray hair and 1 case of mild rash were reported in Group 1, which received a higher dose (continuous triptorelin therapy).

\section{Discussion}

Currently, GnRH analogs are the treatment of choice for precocious puberty as a discrete pediatric disease with substantial physical and psycho-social sequela $(5,7)$. Primarily, treatment of precocious puberty should be directed towards management of the underlying causes. Some studies indicated that medical treatments are more effective in reduction of bone age progression and suppression of puberty in comparison to surgical therapies (5, $8,9)$.

In one study, Bertelloni et al. collected information about the final height of children with central precocious puberty (CPP), who had received no treatment due to delayed diagnosis or rejection by parents (10); they found that the long-term main consequence was reduced adult height. Indeed, untreated individuals depicted a final height of nearly 3 standard deviations below the mean for their values of reference (10). Another study showed that treatment with quarterly triptorelin, similar to monthly administration, permitted to achieve an adult height adequate for mid-parental height in girls with precocious puberty (11). Chiocca et al. evaluated 17 patients (16 girls and 1 boy) with precocious puberty receiving triptorelin $11.25 \mathrm{mg}$ treatment every 90 days and reported suppressed LH peak as well as estradiol levels (12). Compared with other studies, they declared that their treatment method seemed to be more beneficial from first treatment-cycle than that of other GnRH analogs administered quarterly at similar doses. Recently, reports have shown that Histrelin, a GnRH analog, as a subdermal hydrogel implant, decreased stimulated LH concentrations quickly and suppression was maintained for 1 year in 36 subjects (33 girls) (13). After the first year, the authors followed a subset of 
Table 1. Sex Maturity Rates (SMR) and Heights in Group 1 Including Eight Girls With Idiopathic Precocious Puberty (IPP) at First Visit and After a Two-Year Follow Up on Continuous Triptorelin Therapy

\begin{tabular}{|c|c|c|c|c|c|c|c|c|c|c|c|c|}
\hline \multirow[t]{2}{*}{ No } & \multirow[t]{2}{*}{ Age, $y /$ mo } & \multicolumn{2}{|c|}{ SMR } & \multicolumn{9}{|c|}{ Height in Centimeters in Each Visit } \\
\hline & & Breast & Pubic hair & 1st visit & $3^{\mathbf{b}}$ & $6^{b}$ & $9^{b}$ & $12^{b}$ & $15^{b}$ & $18^{b}$ & $21^{b}$ & $24^{b}$ \\
\hline 1 & 7 & II & I & 112 & 114.8 & 116.3 & 117.5 & 118 & 119 & 119.2 & 120.6 & 121.5 \\
\hline 2 & $7 / 4$ & II & I & 110 & 113 & 115 & 116 & 116.5 & 117.5 & 118.7 & 120 & 121 \\
\hline 3 & 6 & II & II & 116 & 118.5 & 120 & 121 & 122 & 123 & 123.8 & 125 & 125.9 \\
\hline 4 & $6 / 4$ & II & II & 113 & 115 & 116.8 & 117.5 & 119 & 119.6 & 120.8 & 122 & 125 \\
\hline 5 & $7 / 4$ & II & II & 119 & 121.3 & 123 & 124.4 & 125.5 & 126 & 127.4 & 128.5 & 129 \\
\hline 6 & $7 / 9$ & II & I & 120 & 123 & 125 & 126.55 & 127.8 & 129 & 130.5 & 131.2 & 132 \\
\hline 7 & $6 / 11$ & II & I & 115 & 117.5 & 119 & 119.5 & 120.5 & 121.6 & 122.5 & 123.2 & 124 \\
\hline 8 & $7 / 8$ & II & II & 118 & 120 & 122.5 & 123 & 124 & 125.3 & 126.5 & 127.7 & 128.5 \\
\hline
\end{tabular}

Table 2. Sex Maturity Rates (SMR) and Heights in Group 2 Including Eight Girls With Idiopathic Precocious Puberty (IPP) at First Aisit and After a Two-Year Follow up on NonContinuous Triptorelin Therapy ${ }^{\mathrm{a}}$

\begin{tabular}{|c|c|c|c|c|c|c|c|c|c|c|c|c|}
\hline \multirow[t]{2}{*}{ No } & \multirow[t]{2}{*}{ Age, $\mathbf{y} / \mathbf{m o}$} & \multicolumn{2}{|c|}{ SMR } & \multicolumn{9}{|c|}{ Height in Centimeter in Each Visit } \\
\hline & & Breast & Pubic hair & 1st visit & $3^{\mathbf{b}}$ & $6^{b}$ & $9^{b}$ & $12^{b}$ & $15^{b}$ & $18^{\mathrm{b}}$ & $21^{\mathbf{b}}$ & $24^{\mathrm{b}}$ \\
\hline 1 & $6 / 2$ & II & II & 109 & 112 & 114 & 116.8 & 118 & 119.2 & 120.5 & 122.5 & 123.2 \\
\hline 2 & 7 & II & II & 116 & 118.8 & 120.5 & 122.5 & 123.7 & 124.2 & 125.8 & 127 & 128.2 \\
\hline 3 & $6 / 9$ & II & I & 118 & 120.5 & 122 & 123.5 & 124.8 & 126.3 & 128 & 129.5 & 130.7 \\
\hline 4 & $7 / 6$ & II & 1 & 114 & 116.7 & 118.5 & 120 & 121.5 & 123 & 124.5 & 126.2 & 128 \\
\hline 5 & 7 & II & II & 115 & 118 & 120.3 & 121.8 & 123.3 & 124.5 & 125.8 & 127.2 & 129.5 \\
\hline 6 & $7 / 8$ & II & I & 111 & 114.6 & 116.5 & 118.5 & 120 & 121.5 & 122.8 & 124.3 & 125.8 \\
\hline 7 & $7 / 9$ & II & II & 121 & 123 & 124.8 & 126 & 126.8 & 128 & 129.5 & 130.4 & 131.3 \\
\hline 8 & $6 / 9$ & II & II & 112 & 114 & 115 & 116.5 & 118 & 118.5 & 119.2 & 120.2 & 121.5 \\
\hline \multicolumn{13}{|c|}{$\begin{array}{l}\text { Abbreviation: SMR, sex maturity rate tanner classification. } \\
\text { a Non-continuous triptrelin thepy: one injection of } 0.3\end{array}$} \\
\hline
\end{tabular}

Table 3. Mean and P Value of Height (Centimeter) in Group I and II After 24 Months

\begin{tabular}{|c|c|c|c|c|c|c|c|c|c|}
\hline Visit & 1st Visit & $3^{a}$ & $6^{a}$ & $9^{a}$ & $12^{\mathrm{a}}$ & $15^{\mathrm{a}}$ & $18^{\mathrm{a}}$ & $21^{a}$ & $24^{\mathrm{a}}$ \\
\hline Group I & 115.37 & 117.88 & 115.37 & 120.68 & 121.66 & 122.62 & 125.86 & 124.77 & 125.86 \\
\hline Group II & 114.50 & 117.20 & 118.95 & 120.70 & 122.01 & 123.15 & 124.51 & 125.91 & 127.27 \\
\hline Pvalue & 0.598 & 0.636 & 0.636 & 1 & 0.916 & 0.793 & 0.636 & 0.600 & 0.49 \\
\hline
\end{tabular}

${ }^{\mathrm{a}}$ Months after first visit.

31 patients having a second implant inserted for another year (14). In a number of the girls previously treated with depot leuprolide-acetate injections, LH levels at study entry were lower, yet, were similarly suppressed at 1 and 2 years from the start of the study $(13,14)$. Over the course of the study, predicted adult height increased by $5.1 \mathrm{~cm}$ in comparison with the baseline predictions. Some adverse events, mainly pain and bruising at the implant insertion site, were seen in $61 \%$ of the patients. The implants became relatively brittle after 1 year, and breakage of the device at removal was common $(13,14)$. Using the implants designed to work for 2 consecutive years also showed similar outcomes compared to using the implants for 1 year (15).
Side-effects, such as gastrointestinal upset, dry skin, alteration in liver function, rash, urticaria, acne, and hair loss have been reported for GnRH analogs $(2,4)$. These side effects were dose-dependent and could be decreased by reducing the drug dose without affecting the final results (2, 4).

In this study, 16 girls with final diagnosis of IPP were divided to 2 equal groups. During 24 months of follow up, patients with continuous triptorelin administration received a total of $7.2 \mathrm{mg} / \mathrm{kg}$ of triptorelin, and the other group with non-continuous administration received a total of 5.4 $\mathrm{mg} / \mathrm{kg}$ or about $39.6 \mathrm{mg}$ of triptorelin less than the other group. During follow up, suppression of hypothalamus- 
pituitary-gonadal axis in both groups was ensured by checking serum estradiol concentrations of more than 10 $\mathrm{pg} / \mathrm{mL}$ and $\mathrm{LH} / \mathrm{FSH}$ less than 1, using the chemiluminescence test (16). No statistically significant differences were noted regarding the height of the 2 groups in visits as well as in the last visit in month 24 .

\subsection{Conclusions}

Regarding the outcome of the present study, treatment of IPP and suppression of hypothalamus-pituitary-gonadal axis can be performed by prescribing lower dose of GnRH agonist while maintaining the therapeutic effects and reducing the side effects.

\section{Acknowledgments}

This study was financially supported by Shiraz University of Medical Sciences, Shiraz, Iran. The authors thank all the staff and researchers of the endocrinology research center of Shiraz University of Medical Sciences, Shiraz, Iran.

\section{Footnotes}

Authors' Contribution: Prof Zohreh Karamizadeh and Dr Forough Saki performed the study design and gathered the data. Dr Ahmad Reza Rasekhi and Prof Sara Kashef helped with gathering the data and patients' follow-ups. Dr Soheil Ashkani-Esfahani helped in data gathering and analysis, writing the manuscript's draft and editing. All the authors helped in writing and revising the manuscript.

\section{Conflicts of Interest: None declared}

\section{References}

1. Karamizadeh Z, Kashef MA, Jalaeian H, Namazee N. Combined use of growth hormone and gonadotropin-releasing hormone analogue in short normal adolescent girls: a survey from Iran. Kaohsiung J Med Sci. 2006;22(4):161-5. doi: 10.1016/S1607-551X(09)70301-8. [PubMed: 16679296].

2. Karamizadeh Z, Rasekhi AR. Gray hair in children on triptorelin treatment. Int J Dermatol. 2008;47(6):601-4. doi: 10.1111/j.13654632.2008.03602.x. [PubMed: 18477156].
3. Crowley WJ, Comite F, Vale W, Rivier J, Loriaux DL, Cutler GJ. Therapeutic use of pituitary desensitization with a long-acting lhrh agonist: a potential new treatment for idiopathic precocious puberty. J Clin Endocrinol Metab. 1981;52(2):370-2. doi: 10.1210/jcem-52-2-370. [PubMed: 6780592].

4. Lahlou N. [Pharmacokinetics and pharmacodynamics of triptorelin]. Ann Urol (Paris). 2005;39 Suppl 3:S78-84. [PubMed: 16302716].

5. Fuqua JS. Treatment and outcomes of precocious puberty: an update. J Clin Endocrinol Metab. 2013;98(6):2198-207. doi: 10.1210/jc.2013-1024. [PubMed: 23515450].

6. Kreiter M, Burstein S, Rosenfield RL, Moll GJ, Cara JF, Yousefzadeh DK, et al. Preserving adult height potential in girls with idiopathic true precocious puberty. J Pediatr. 1990;117(3):364-70. [PubMed: 2144020].

7. Partsch CJ, Heger S, Sippell WG. Management and outcome of central precocious puberty. Clin Endocrinol (Oxf). 2002;56(2):129-48. [PubMed: 11874402].

8. Klein KO, Barnes KM, Jones JV, Feuillan PP, Cutler GJ. Increased final height in precocious puberty after long-term treatment with LHRH agonists: the National Institutes of Health experience. J Clin Endocrinol Metab. 2001;86(10):4711-6. doi: 10.1210/jcem.86.10.7915. [PubMed: 11600530].

9. Stewart L, Steinbok P, Daaboul J. Role of surgical resection in the treatment of hypothalamic hamartomas causing precocious puberty. Report of six cases. J Neurosurg. 1998;88(2):340-5. doi: 10.3171/jns.1998.88.2.0340. [PubMed: 9452248].

10. Bertelloni S, Mul D. Treatment of central precocious puberty by GnRH analogs: long-term outcome in men. Asian J Androl. 2008;10(4):52534. doi: 10.1111/j.1745-7262.2008.00409.x. [PubMed: 18478155].

11. Bertelloni S, Massart F, Einaudi S, Wasniewska M, Miccoli M, Baroncelli GI. Central Precocious Puberty: Adult Height in Girls Treated with Quarterly or Monthly Gonadotropin-Releasing Hormone Analog Triptorelin. Horm Res Paediatr. 2015;84(6):396-400. doi: 10.1159/000441497. [PubMed: 26528763].

12. Chiocca E, Dati E, Baroncelli GI, Cassio A, Wasniewska M, Galluzzi F, et al. Central precocious puberty: treatment with triptorelin 11.25 mg. ScientificWorldJournal. 2012;2012:583751. doi: 10.1100/2012/583751. [PubMed: 22645436].

13. Eugster EA, Clarke W, Kletter GB, Lee PA, Neely EK, Reiter EO, et al. Efficacy and safety of histrelin subdermal implant in children with central precocious puberty: a multicenter trial. J Clin Endocrinol Metab. 2007;92(5):1697-704. doi: 10.1210/jc.2006-2479. [PubMed: 17327379].

14. Rahhal S, Clarke WL, Kletter GB. Results of a second year of therapy with the 12-month histrelin implant for the treatment of central precocious puberty. Int J Pediatr Endocrinol. 2009;1:1. doi: $10.1155 / 2009 / 812517$.

15. Lewis KA, Eugster EA, editors. Continual suppresion by the histrelin implant for the treatment of central precocious puberty when left in place for two years. Pediatric Academic Societies Meeting. 2011; p. abstract.

16. Kletter GB. How should we diagnose and monitor central precocious puberty?. J Pediatr Endocrinol Metab. 2008;21(12):1105-6. [PubMed: 19189680]. 